\title{
In ble sefer.
}

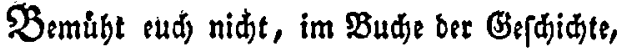
Der Zuelle meines libbes nadzurpuren.

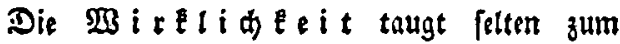

Gedid)te,

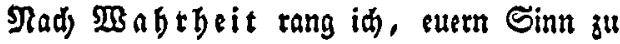
túbren;

Nadh jenet $\mathfrak{B a b r b t i t , ~ d i e ~ i m ~ I r a u m g e f i d t e ~}$ Die Mujen vor bes Beiftes Zluge fübren.

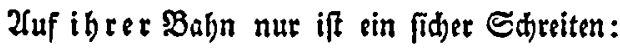
Bas niemals war, bas ift bu allen seiten. 

$\mathfrak{R} \mathfrak{d} \mathfrak{n} \mathfrak{i} \mathfrak{g} \quad \mathfrak{Y} \mathfrak{n} \mathfrak{g} \mathfrak{u} \mathfrak{r} \mathfrak{d}$. 
